\title{
LAJU PERTUMBUHAN KARANG Acropora formosa YANG DITRANPLANTASI PADA MEDIA TEMPEL DAN MEDIA GANTUNG
}

\author{
(Growth rate of transplanted corals of Acropora formosa on fixed and hanging media)
}

\author{
Stevania M. Runtuwene ${ }^{1^{\star}}$, Indri S. Manembu ${ }^{1}$, Noldy G.F. Mamangkey ${ }^{1}$, Antonius P. \\ Rumengan', Darus Sa'adah J. Paransa', Hariyani Sambali ${ }^{2}$
}

1. Program Studi Ilmu Kelautan, FPIK Unsrat Manado.

2. Jurusan Manajemen Sumberdaya Perairan, FPIK Unsrat Manado.

*e-mail: 16051103048@student.unsrat.ac.id

\begin{abstract}
Corals are associations of millions polyps that live in symbiotic way with zooxanthellae algae. Most of the polyps live in colonies and form a reef. Coral reefs are rich ecosystems that contain diverse organisms living in it. However, the threat of damage increases with the pressure that enters the waters. Coral transplantation is one way of restorations that can be done to restore damaged corals by cutting live corals and then planting them in places where the corals have been damaged. This study aims to determine the growth rate of Acropora formosa corals that were transplanted on fixed and hanging media. Data was collected in Malalayang Coast Waters, Manado City, North Sulawesi. The research took place for seven months. Beginning with the coral transplant activity of Acropora formosa on fixed and hanging media, then continued with monitoring every month for six months. Transplanted corals were measured using a ruler to determine the length of the coral from the beginning to the end of the study and then the data was analyzed using Microsoft Excel. The results obtained for the average growth rate of Acropora formosa corals transplanted on fixed media were $0.8 \mathrm{~cm}$ and on hanging media $1.8 \mathrm{~cm}$. Overall growth rate averaged 1.3 $\mathrm{cm}$.

Keywords: Coral, Coral Reef, Transplant, Acropora formosa.

Karang merupakan kumpulan dari berjuta hewan polip yang hidup bersimbiosis dengan algae zooxanthellae. Sebagian besar hewan polip ini hidup berkoloni dan membentuk suatu terumbu. Terumbu karang merupakan ekosistem yang kaya akan keanekaragaman biota di dalamnya. Namun demikian, ancaman kerusakan meningkat bersama tekanan yang masuk ke dalam perairan. Transplantasi karang merupakan salah cara yang dapat dilakukan untuk pemulihan karang yang telah rusak dengan cara memotong karang yang masih hidup kemudian di tanam di tempat yang karangnya telah mengalami kerusakan. Penelitian ini bertujuan untuk mengetahui laju pertumbuhan karang Acropora formosa yang ditransplantasi pada media tempel dan gantung. Pengambilan data dilakukan di Perairan Pantai Malalayang, Kota Manado, Sulawesi Utara. Pelaksanaan penelitian berlangsung selama tujuh bulan. Diawali dangan kegiatan transplantasi karang jenis Acropora formosa pada media tempel dan gantung, kemudian dilanjutkan dengan monitoring setiap bulan selama enam bulan. Karang yang telah ditransplantasi diukur menggunakan mistar untuk mengetahui panjang karang tersebut dari awal hingga akhir penelitian dan selanjutnya data tersebut dianalisis menggunakan Microsoft Excel. Hasil penelitian yang didapat untuk laju pertumbuhan rata-rata karang Acropora formosa yang ditransplantasikan pada media tempel sebesar $0.8 \mathrm{~cm}$ dan pada media gantung $1.8 \mathrm{~cm}$. Secara keseluruhan laju pertumbuhan ratarata sebesar $1.3 \mathrm{~cm}$.
\end{abstract}

Kata Kunci: Karang, Terumbu karang, Transplantasi, Acropora formosa. 


\section{PENDAHULUAN}

Terumbu karang merupakan ekosistem yang paling indah karena memiliki bentuk dan warna yang beragam serta memiliki keanekaragaman hayati yang tinggi. (Nybakken, 1992 dalam Pustikawati 2016). Berdasarkan citra satelit, diperkirakan luasan terumbu karang di Indonesia adalah 2.5 juta hektar. Kondisi terumbu karang di Indonesia pada kategori jelek sebanyak $36,18 \%$, terumbu karang kategori cukup sebanyak $34,3 \%$ terumbu karang kategori baik sebanyak $22,96 \%$, dan kategori sangat baik sebanyak 6,56\% (Hadi dkk, 2018). Kerusakan yang disebabkan oleh dua faktor yaitu aktivitas manusia dan faktor alam. Kerusakan terumbu karang dapat disebabkan oleh aktivitas manusia seperti penangkapan ikan yang merusak (Arini, 2013; Manembu, 2014), limbah padat (Wahyulfatwatul $d k k, 2017)$ dan eksploitasi karang secara illegal untuk keperluan perdagangan (Ramses, 2018). Sedangkan kerusakan yang disebabkan oleh faktor alam seperti tsunami, badai, kadar garam yang tidak normal, kurangnya cahaya maupun akibat adanya predasi karang (Boneka dan Mamangkey, 2013). Perairan Pantai Malalayang terdapat di wilayah Perairan Teluk Manado, memiliki terumbu karang yang potensial dikembangkan. Seperti yang diketahui Pantai Malalayang merupakan salah satu tempat wisata. Keindahan bawah laut yang ada di pantai Malalayang dapat menarik perhatian masyarakat untuk datang berwisata. Perairan pantai Malalayang dapat dijadikan sebagai wisata selam khususnya bagi para penyelam pemula yang ini melakukan kegiatan penyelaman. Banyak masyarakat local maupun mancanegara yang datang berwisata di tempat ini untuk menyelam atau menikmati kuliner yang ada. Untuk itu terumbu karang yang ada di pantai Malalayang harus terus dilestarikan karena sangat disayangkan jika terumbu karang yang terdapat di perairan tersebut tidak dijaga dan dilindungi. Perairan Pantai Malalayang tidak luput dari ancaman yang dapat merusak ekosistem terumbu karang. Kerusakan karang yang terjadi di Perairan Pantai Malalayang dapat disebabkan oleh berbagai aktivitas manusia seperti reklamasi pantai, peletakan jangkar dan sampah yang dibuang sembarangan. Usaha untuk pemulihan terumbu karang sangat dibutuhkan untuk memperbaiki keadaan ekosistem terumbu karang. Berbagai cara bisa dilakukan diantaranya dengan melakukan transplantasi karang. Transplantasi karang adalah suatu metode penanaman dan pertumbuhan suatu koloni karang dengan cara fragmentasi atau memotong karang yang masih hidup dan di tanam ditempat lain bertujuan untuk pemulihan karang yang telah rusak atau pembentukan terumbu karang alami (Taufina $d k k, 2018$ ). Acropora adalah salah satu genus karang yang memiliki tingkat ketahanan hidup yang besar dan kecepatan pertumbuhan yang tinggi.

\section{METODE PENELITIAN}

\section{Waktu dan Tempat Penelitian}

Penelitian ini dilaksanakan selama kurang lebih tujuh bulan. Bertempat di dua lokasi yaitu tempat pembuatan rak trasplantasi di Fakultas Perikanan dan IImu Kelautan Universitas Sam Ratulangi Manado dan Tempat pelaksaan transplantasi karang di Perairan Pantai Malalayang, Kecamatan Malalayang, Kota Manado. 




Gambar 1. Peta lokasi transplantasi

Sumber: Google Earth Imagery (2018)

\section{Alat dan Bahan}

Alat yang digunakan; mobil pick up, perahu, peralatan SCUBA (Self-Contained Underwater Breathing Apparatus), kamera underwater, kamera telepon, keranjang, tang, mistar, sabak, sarung tangan, GPS (Global Positioning System), termometer, refraktometer, $\mathrm{pH}$ meter, secchi disk, wadah, map plastic.Bahan yang digunkan; Fragmen Karang (spesies Acropora formosa), besi, senar, kabel ties, pipa, sambungan pipa, lem pipa, semen, pasir, kerikil.

\section{Pembuatan Rak dan Substrat}

Dalam penelitian ini terdapat 2 jenis rak yang berbeda yaitu yang pertama rak besi dan yang kedua rak pipa. Rak besi akan dibuat dari besi batangan yang kemudian dibentuk menjadi tiga rak menyerupai kerangka huruf
E, V, dan A. Kegunaan dari rak besi ini adalah sebagai tempat mengikat senar, sedangkan senar itu digunakan sebagai tempat mengikat fragmen karang. Rak pipa terbuat dari pipa paralon yang kemudian akan dibentuk menjadi tiga rak yang menyerupai kerangka $E, V$, dan $A$. Kegunaan dari rak paralon ini adalah sebagai tempat substrat. Substrat yang digunakan terbuat dari campuran semen, pasir dan kerikil. Campuran tersebut dimasukan dalam cetakan pipa paralon yang berukuran 1inch dengan panjang $10 \mathrm{~cm}$ dan ditengah-tengahnya terdapat besi batangan dengan panjang $20 \mathrm{~cm}$ yang berfungsi sebagai tempat ditempelkannya fragmen karang. Masing-masing rak dilengkapi dengan kaki dan pemberat agar tidak terbawa arus. 


\section{Penentuan Jenis Karang}

Jenis karang yang digunakan untuk trasplantasi ini adalah karang spesies Acropora formosa. Harriott dan Fisk (1998) menyatakan bahwa karang Acropora branching sangat cocok digunakan sebagai fragmen karang untuk kegiatan transplantasi karena memiliki tingkat ketahanan hidup yang tinggi dan pertumbuhannya relatif cepat.

\section{Penentuan Fragmen}

Ukuran fragmen karang yang digunakan dalam kegiatan transplantasi berkisar antara 7-15 cm. Besarnya ukuran fragmen transplantasi sangat menentukan keberhasilan transplantasi karang. Dalam transplantasi karang Acropora sp. harus memperhatikan ukuran karang tersebut, karena ukuran yang lebih kecil akan berpotensi memiliki tingkat kematian yang tinggi. (Johan $d k k, 2008$ ).

\section{Peletakan Rak Transplantasi}

Rak transplantasi yang berada di darat, dibawa menggunakan perahu menuju ke laut. Setelah sampai di lokasi rak transplantasi tersebut akan dibawa hingga ke dasar perairan pada kedalaman 7-9 m dengan menggunakan bantuan alat selam untuk pernafasan di dalam air, kemudian di letakan sejajar antara rak satu dengan yang lainnya.

\section{Pengambilan Bibit dari Induk Karang}

Induk karang yang digunakan diambil dari lokasi yang berdekatan dengan lokasi transplantasi, induk tersebut difragmentasi menggunakan tang menjadi koloni yang terpotong (fragmen). Fragmen karang yang telah diambil dari induknya, kemudian dimasukkan ke dalam keranjang yang selanjutnya akan dibawa ke tempat transplantasi

\section{Pemasangan Fragmen}

Untuk rak pipa, fragmen karang yang telah dikumpulkan diikat menggunakan ties pada masing-masing besi yang terdapat pada setiap substrat semen. Sedangkan pada rak besi fragmen karang diikat pada senar yang di gantung. Pada masing-masing fragmen diberi tanda dengan menggunakan map plastik yang telah di potong-potong menjadi kecil.

\section{Pengamatan Pertumbuhan Karang dan Analisis Data}

Pengamatan dilakukan setiap bulan, dengan cara mengukur panjang karang yang ditransplantasi menggunakan mistar untuk mengetahui pertumbuhan karang. Selanjutnya data pertumbuhan panjang karang dianalisis menggunakann bantuan Microsoft Excel.

\section{Laju Pertumbuhan}

Laju pertumbuhan karang dihitung menggunakan rumus merujuk pada (Ricker dalam Joni $d k k, 2015)$ :

$$
\mathrm{P}=(\mathrm{Lt}-\mathrm{L} 0) /(\mathrm{t})
$$

Keterangan:

P: Pertambahan panjang/tinggi karang

Lt: Rata-rata panjang/tinggi setelah pengamatan ke-t

L0: Rata-rata panjang/tinggi awal penelitian

T: Waktu pengamatan (bulan) 


\section{Pengukuran Parameter Perairan}

Pengukuran kualitas perairan diperlukan untuk mengetahui karakteritik biofisik dari

suatu perairan (Manembu dkk, 2012). Parameter perairan yang diukur yaitu suhu, salinitas, ph, kecerahan dan kedalaman.

\section{HASIL DAN PEMBAHASAN}

\section{Laju Pertumbuhan}

Ukuran pertumbuhan dari fragmen yang ditransplantasikan pada media temepel dan media gantung sejak awal penelitian yaitu bulan Mei 2019 sampai dengan akhir penelitian pada bulan Oktober 2019 menunjukan nilai yang berbeda-beda. Ratarata pertambahan panjang fragmen karang pada setiap bulan dapat dilihat pada grafik dibawah ini:

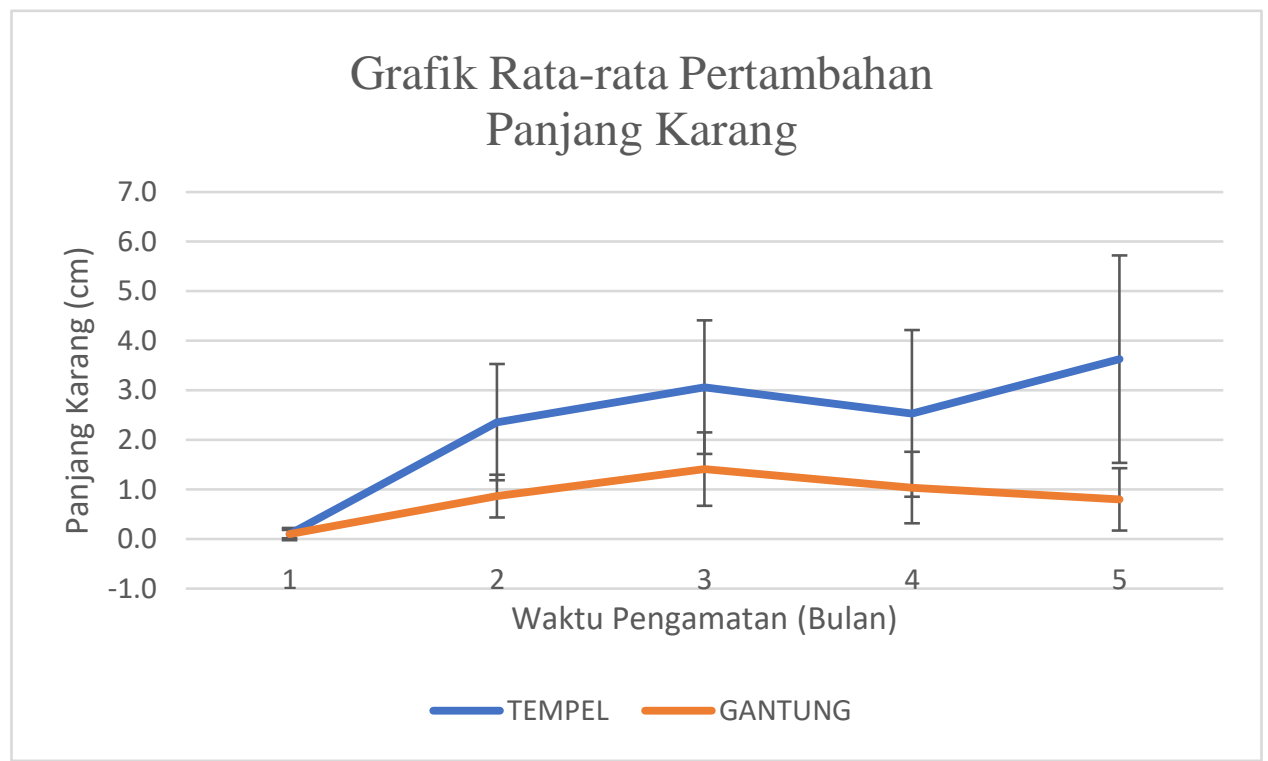

Gamba 2: Grafik rata-rata pertambahan panjang fragmen karang (cm $\pm S D)$

Berdasarkan hasil penelitian yang ditunjukan pada grafik di atas, rata-rata pertambahan panjang karang Acropora formosa pada kedua media menunjukkan adanya peningkatan yang cukup baik. Ratarata pada media tempel mengalami peningkatan pada bulan pertama hingga bulan ketiga; bulan pertama $0.1 \mathrm{~cm}$, bulan kedua $0.8 \mathrm{~cm}$, bulan ketiga $1.4 \mathrm{~cm}$. Pada bulan keempat mengalami penurunan yaitu menjadi $1 \mathrm{~cm}$ dan pada bulan kelima kembali meningkat yaitu $1.2 \mathrm{~cm}$. Hal yang sama juga terjadi pada media gantung dimana pada bulan pertama hingga bulan ke tiga rata-rata pertambahan panjang karang mengalami peningkatan yaitu $0.1 \mathrm{~cm}, 2 \mathrm{~cm}, 2.8 \mathrm{~cm}$.
Namun mengalami penurunan pada bulan keempat yaitu $2.3 \mathrm{~cm}$ dan kembali meningkat pada bulan kelima yaitu $3.4 \mathrm{~cm}$.

Pertambahan panjang dari fragmen karang dipengaruhi oleh faktor lingkungan seperti suhu, salinitas, $\mathrm{pH}$, kecerahan dan kedalaman. Berdasarkan hasil penelitian yang dilakukan di perairan Pantai Malalayang, dapat diketahui bahwa kondisi perairan Pantai Malalayang masih tergolong baik karena parameter yang diukur tidak berbeda jauh dengan baku mutu menurut Keputusan Menteri Lingkungan Hidup No. 51 tahun 2004. 
Tabel 1. Hasil Pengukuran Kuslitas Perairan Pantai Malalayang

\begin{tabular}{|c|c|c|}
\hline Parameter Kualitas Air & $\begin{array}{c}\text { Kisaran Hasil } \\
\text { Pengukuran }\end{array}$ & $\begin{array}{c}\text { Baku Mutu Kepmen LH } \\
\text { No. 51,2004 }\end{array}$ \\
\hline Suhu & $29-31^{\circ} \mathrm{C}$ & $28-30^{\circ} \mathrm{C}$ \\
\hline Salinitas & $28-29 \mathrm{ppt}$ & $23-35 \mathrm{ppt}$ \\
\hline $\mathrm{pH}$ & 7.35 & $7-8,5$ \\
\hline Kedalaman & $7.5-9 \mathrm{~m}$ & $<20$ \\
\hline Kecerahan & $8-9$ & $>5$ \\
\hline
\end{tabular}

Kegiatan transplantasi ini dapat dikatakan berhasil karena fragmen karang yang ditransplantasi mengalami pertumbuhan dengan baik. Penurunan pertambahan panjang pada bulan September diduga terjadi karena pada bulan itu, suhu mengalami kenaikan yaitu menjadi
$31{ }^{\circ} \mathrm{C}$. Suhu mempengaruhi kecepatan metabolisme reproduksi dan perombakan bentuk luar dari karang (Sadarun et al., 2006 dalam Prayoga $d k k, 2019)$. Suhu yang relatif konstan sangat baik untuk pertumbuhan, sebaliknya jika terjadi keinaikan suhu maka akan mengancam kehidupan karang.



Gambar 3. Rata-rata laju pertumbuhan karang Acropora formosa ( \pm SD)

Rata-rata laju pertumbuhan karang Acropora formosa pada media gantung menunjukkan nilai yang lebih tinggi yaitu 1.8 $\mathrm{cm}$ jika dibandingkan dengan nilai laju pertumbuhan rata-rata pada media tempel yaitu $0.8 \mathrm{~cm}$. Rata-rata laju pertumbuhan karang secara keseluruhan yaitu sebesar 1.3 $\mathrm{cm}$. Penelitian lain tentang laju pertumbuhan karang Acropora telah dilakukan sebelumnya oleh Iswara (2010) di Pulau Kelapa dengan pengamatan selama enam bulan memperoleh nilai laju pertumbuhan 
$0.85 \mathrm{~cm} /$ bulan. Sedangkan Tioho (2013) di perairan Kalasey dengan pengamatan satu tahun memperoleh nilai laju pertumbuhan pada kisaran antara $0.81-0.94 \mathrm{~cm} / \mathrm{bulan}$ dan Mompala dkk (2017) di perairan Kareko selama empat bulan sebesar $0,96 \mathrm{~cm} / \mathrm{bulan}$.

\section{PENUTUP}

\section{Kesimpulan}

Berdasarkan hasil penelitian yang dilakukan, maka dapat disimpulkan bahwa: Laju pertumbuhan rata-rata karang Acropora formosa yang ditransplantasikan pada media tempel sebesar $0.8 \mathrm{~cm}$ dan pada media gantung $1.8 \mathrm{~cm}$. Secara keseluruhan laju pertumbuhan rata-rata sebesar $1.3 \mathrm{~cm}$.

\section{DAFTAR PUSTAKA}

Arini D.I.D. 2013. Potensi terumbu karang Indonesia: Tantangan dan upaya konservasinya. INFO BPK Manado. Vol 3. No 2: 147-172.

Boneka, F. B., Mamangkey, N. G. F. 2013. Abundance of coral-polyp-eating gastropods Drupella cornus in Bunaken National Park, Indonesia: indicating anthropogenic impact? Aquatic Science \& Management. 1 (1): $17-20$.

Hadi T.A., Giyanto., Prayudha, B., Hafizt, M., Budiyanto, A. dan Suharsono. 2018. Status terumbu karang Indonesia 2018. Pusat Penelitian Oseanografi Lembaga IImu Pengetahuan Indonesia, Jakarta.

Harriot, V.J. and Fisk, D.A. 1988. Coral transplation as reef management option. Proceedings of the 6th
International Coral Reef Syimposium 2: $375-379 p$.

Iswara, S. 2010. Analisis Laju Pertumbuhan Dan Kelangsungan Hidup Karang Acropora Spp., Hydnopora Rigida, Dan Pocillopora Verrucosa Yang Ditransplantasikan Di Pulau Kelapa, Kepulauan Seribu. Skripsi. Departemen Manajemen Sumberdaya Perairan. FPIK-IPB. Bogor.

Johan O., Dedi, S. dan Suharsono. 2008. Tingkat keberhasilan transplantasi karang batu (stony coral) di Pulau Pari, Kepulauan Seribu, Jakarta. Vol 3, No 2:289-300.

Joni., Pratomo A., Irwan H. 2015. Laju pertumbuhan dan tingkat kelangsungan hidup karang Acropora formosa hasil transplantasi pada kedalaman berbeda. Jurnal.FPIKUMRAH.

Manembu, I.S., Adrianto, L., Begen, D.G. dan Yulianda, F. 2012. Distribusi karang dan ikan karang di Teluk Buyat Kabupaten Minahasa Tenggara. Jurnal Perikanan dan Kelautan tropis. Vol. VIII-1: 28-32.

Manembu, I.S., Adrianto, L., Bengen, D., Yulianda, F. 2014. Kelimpahan ikan karang pada Kawasan terumbu buatan di Perairan Ratatotok Sulawesi Utara. BAWAL. Vol 6(1). Hal 55-61.

Mompala, K., Rondonuwu A.B., Rembet, U.N.W.J. Laju pertumbuhan karang batu Acropora sp. yang ditransplantasi pada terumbu buatan di Perairan Kareko Kecamatan Lembeh Utara Kota 
Bitung. Jurnal IImiah Platax. Vol 5(2). Hal 234-242.

Prayoga, B., Munasik., Irwani. 2019. Perbadaan metoden transplantasi terhadap laju pertumbuhan Acropora aspera pada artificial patch reef di Pulau Panjang Jepara. Journal of Marine Research. Vol 8(1). Hal 1-10.

Pustikawati, M., Johan Y., dan Hartono D. 2016. Kajian ekosistem terumbu karang untuk pengembangan ekowisata bahari Pulau Tikus Bengkulu. Jurnal Enggano. Vol 1(1). Hal 113-119.

Ramses. 2018. Kondisi dan keragaman karang hias di Perairan Pulau Sarang dan sekitarnya, Kecamatan Bekalang Padang, Kota Batam. SIMBIOSA. Vol (2): 57-66.

Taufina., Faisal., Stelly M.L.2018. Rehabilitasi Terumbu Karang Melalui Kolaborasi Terumbu Buatan dan Trasplantasi Karang Di Kecamatan Bungus Teluk Kabung Kota Padang: Kajian Deskriptif Pelaksanaan Corporate Social Responsibility (CSR) PT. Pertamina (Persero) Marketing Operation Region (MOR) I - Terminal Bahan Bakar Minyak (TBBM) Teluk Kabung. Jurnal Pengabdia Kepada Masyarakat. Vol 24. No 2.

Tioho, H., Paruntu, C.P. dan Patrich, H. (2013) Ketahanan Hidup Dan Laju Pertumbuhan Karang Scleractinia Yang Ditransplantasi Pada Rataan Terumbu Perairan Kalasei, Kabupaten Minahasa, Sulawesi Utara.Aquatic Science \&
Management, Vol. 1, No. 2, 111116.

Wahyulfatwatul UAS., Litaay, M., Priosambodo, D. dan Moka, W. 2017. Genera karang keras di Pulau Barrang Lompo dan Bone Batang berdasarkan metode identifikasi coral finder. Jurnal Biologi Makasar. Vol 2(2): 39-51. 